\title{
COMMUNICABLE DISEASES REPORT, NSW, FOR MAY-JUNE 2004
}

For updated information, visit the website www.health.nsw.gov.au and click on the link to Infectious Diseases.

\section{TRENDS}

Tables 7 and 8 and Figure 2 show reports of communicable diseases received for May and June 2004 in New South Wales (NSW).

This month we include, for the first time, a regular graph of notifications of outbreaks of gastroenteritis in institutions in Figure 2 (see report below). Reports of arbovirus infections declined after a peak in April associated with increased activity of infective mosquitoes. Notifications of cryptosporidiosis continued to decline, following the summer peak that was most likely associated with person-to-person spread and possibly with swimming in contaminated swimming pools. Reports of Legionnaires' disease also declined after peaking in April, although no common source of infection was identified in that month. Reports of meningococcal disease have begun to increase in line with the expected winter-spring peak in incidence (see report below). Reports of pertussis declined further in May and June. After a large peak in autumn, reports of salmonellosis are finally beginning to fall (see report below). No cases of measles were reported in June. The Mid North Coast Public Health Unit investigated a large outbreak of Salmonella Typhimurium 135 in June. The outbreak occurred in a rehabilitation centre and affected 43 residents and staff.

\section{GASTROENTERITIS OUTBREAKS IN INSTITUTIONS}

In May 2004, 58 gastroenteritis outbreaks in institutional settings, affecting over 1,200 people, were reported in NSW. Outbreaks occurring in institutions are more common in the winter months and are usually caused by norovirus. Of these 58 outbreaks, 76 per cent were reported from aged-care facilities, 19 per cent from hospitals, two per cent from childcare centres, and two per cent from hostels. In 19 per cent of these outbreaks, norovirus was identified from stool samples. The epidemiological features of the other outbreaks were largely consistent with norovirus (symptoms of vomiting and diarrhoea lasting 24-48 hours, associated with spread to others). Because aged-care facilities and hospitals are regulated by health authorities, reporting from these institutions is likely to be more complete than from other institutions. In addition, reports of outbreaks of gastroenteritis from these institutions after January 2004 are likely to be more complete than in previous years, after the NSW Department of Health alerted managers of the importance of notification.
The rapid control of such outbreaks is vital. Measures include:

- careful review of infection control measures, including reinforcing the importance of hand washing among staff, patients, and visitors;

- sick health care and food service workers should avoid work that includes patient care or food handling for at least 48 hours after symptoms cease;

- reporting all outbreaks to the local public health units, where staff can provide expert advice on their management.

For more information see the Gastroenteritis (viral) fact sheet on the infectious diseases web page at www.health. nsw.gov.au/living/infect.html.

\section{SALMONELLOSIS OUTBREAK}

Salmonellosis is an infection of the gut that results in diarrhoea, vomiting, and fever. Many different types (or serovars) of Salmonella bacteria can cause salmonellosis. There were 1,157 cases of salmonellosis reported in NSW with onset from January to May 2004, of which 173 were caused by infection with Salmonella Typhimurium phage type 170 (STM170) (this number is likely to increase as further information on untyped cases is received). By comparison, there were 1,060 cases reported for the same period in 2003, of which 127 were due to STM170. Much of the increase in NSW occurred since January 2004; however, cases were not unusually clustered by place of residence, age, or sex.

Four separate outbreaks of STM170, where a likely common source of infection has been identified, have occurred to date in 2004. These include:

- 12 cases among a group of 14 people who shared a barbequed chicken and rice meal at a catered lunch in South Western Sydney in February;

- four cases who ate barbeque chicken from a takeaway shop in New England in April;

- 17 cases who ate chicken dishes from a restaurant in New England in April. STM170 was isolated from cooked chicken;

- 15 cases who ate chicken wraps from a cafe in Northern Sydney in April.

While the source of infection for most STM170 cases remains obscure, eating meats (including chicken) that have been incompletely cooked, or eating other foods that have been contaminated by raw meats (including chicken) is a likely source for many. Salmonellosis can be avoided by the thorough cooking of meats known to be at risk of contamination, including hamburgers and poultry. These should not be eaten if the meat remains 
pink. The cooking of other meats, such as steak and chops, on the outside is probably sufficient to reduce the risk of infection. Avoid allowing raw meat to come into contact with partially-cooked foods that are not cooked further before eating. Do not allow fluids from meats to drip onto other foods in the refrigerator, and do not use the same cutting board and knife to prepare salads or other ready to eat foods without careful washing of the cutting board, knife, and hands.

For more information see the Salmonellosis fact sheet on the infectious diseases web page at www.health.nsw.gov.au/ living/infect.html.

\section{MENINGOCOCCAL DISEASE}

Between 180 and 250 cases of meningococcal disease are reported annually in NSW. The incidence increases in winter and early spring. To the end of May, 56 cases were reported in NSW for 2004, the same number as for this period last year. Of the 56 cases in 2004, 43 per cent ( 24 cases) were due to infection with meningococcus serogroup B, 16 per cent ( 9 cases) with serogroup C, and for 41 per cent (23 cases) the serogroup is pending or unknown. For the same period last year, 46 per cent were due to serogroup B, 18 per cent to serogroup C, 5 per cent to serogroup Y, 2 per cent to serogroup W135, and 29 per cent to an unknown serogroup. Two deaths have been reported for 2004. For the same period last year one death was reported, although there were a total of 14 deaths reported for all of 2003.

While meningococcal bacteria are transferred from personto-person through secretions from the nasopharynx of an infected person, recent evidence indicates that contact with saliva is not an important risk. ${ }^{1}$ Activities such as kissing, and sharing of food, drinks and cigarettes with a case are unlikely to lead to transmission of disease.

Meningococcal $\mathrm{C}$ vaccine is now routinely recommended to all children at 12 months of age. In addition, all children $1-5$ years of age are eligible for free vaccine through their local general practitioner. Since August 2003, more than 550,000 children in NSW have been immunised through NSW Health's school-based immunisation program.

Suspected cases should be immediately treated with intramuscular or intravenous antibiotics, although the intravenous route is preferable. The collection of diagnostic samples (including blood, cerebrospinal fluid, and skin rash aspirates) are important in confirming the diagnosis, through microscopy, culture, polymerase chain reaction testing, and serology. Guidelines for the early clinical and public health management of meningococcal disease in Australia can be found at www.cda.gov.au/pubs/ other/mening.htm.

For more information see the Meningococcal disease fact sheet on the infectious diseases web page at www.health.nsw.gov.au/living/infect.html.

\section{Reference}

1. Orr HJ, Gray SJ, MacDonald M, Stuart JM. Saliva and meningococcal transmission. Emerg Infect Dis 2003; 9: 13141315 .

\section{HEPATITIS A CLUSTER IN A SCHOOL}

South Western Sydney Public Health Unit reported a cluster of five cases of hepatitis A among children attending a primary school in Sydney in June. Hepatitis A is caused by the hepatitis A virus, which is easily spread by the faecal-oral route, either directly from person-toperson or indirectly via contaminated food or water. After an incubation period of about a month, symptoms begin that can include fever, malaise, nausea, abdominal discomfort, and sometimes vomiting and diarrhoea. A few days later jaundice may occur. Patients are generally unwell for several days to several weeks but many people who are infected can have mild or no obvious symptoms. The likelihood of having symptoms increases with age. Symptoms may be atypical in young children. Cases are infectious for about two weeks before the onset of jaundice until about one week after jaundice appears. Infection is confirmed by the detection of $\operatorname{IgM}$ antibodies in the patient's blood.

The first case (Case A) was a child who most likely acquired the infection while travelling. Case A developed jaundice in mid-May and returned to school three days later. Thirteen days after Case A returned to school, Case B developed jaundice, and Cases C and D developed jaundice over the subsequent 11 days. Apart from attending the same class, no other links among the cases could be identified. Within the classroom, there were no common specific risk factors (such as common foods or social gatherings) that could be identified among the cases. However, the class teacher reported that the class has a common lolly-jar from which all children in the class could choose lollies.

It was hypothesized that lollies from the lolly-jar may have been inadvertently contaminated by a person with hepatitis A (who may have been asymptomatic at the time) and that the jar could have been a source of infection for Cases B, C and D. As all but one of the children in the class were regular users of the lolly-jar, and therefore at potential risk of infection, the entire class (apart from the recognised cases) was offered normal human immunoglobulin in an attempt to reduce further illness.

Subsequently, a fifth student at the school (Case E) was diagnosed with hepatitis A. Case E attended a different class but was a sibling of an asymptomatic classmate of Cases A, B, C and D who had received Normal human immunoglobulin. Case E first became unwell 17 days after case B first developed symptoms. South Western Sydney Public Health Unit staff counselled and tested the family of Case E for hepatitis A. Case E's sibling, as well as Cases A, B, C, D, and E, all tested positive for hepatitis A IgM. 
The source of infection for this cluster remains obscure, although contamination of the lolly-jar by an infectious person remains the most likely explanation. The lack of contact among cases during Case A's infectious period and the subsequent cases' incubation periods suggests that Case A was unlikely to be the source of infection for Cases B, C, D, or E. Because a large proportion of hepatitis A infections in children remain asymptomatic, it is possible that the lolly-jar, or some other identified food or environmental source, was contaminated by a person in the class with unrecognised-yet infectious-hepatitis A infection. Case E was most likely infected through contact with their sibling.

This cluster highlights several important public health issues. First, although hepatitis A outbreaks in school settings are very unusual, the diagnosis (and confirmatory testing) should be considered in children with consistent symptoms. Second, transmission from unrecognised cases may play an important role in clusters, and should be considered in such investigations. Third, care should be taken to ensure that foods to be shared (such as lollies, snacks, or nibbles) are offered in such a way as to avoid contamination by people's hands.

\section{QUARTERLY REPORT: AUSTRALIAN CHILDHOOD IMMUNISATION REGISTER}

Table 1 details the percentage of fully immunised children aged 12 months to less than 15 months in each area health service, reported by all service providers.

These data refer to five different cohorts of children whose age has been calculated 90 days before data extraction. The information contained in each of the reports has been extracted from the Australian Childhood Immunisation Register (ACIR) and may be underestimated by approximately three per cent due to children being

\section{TABLE 1}

\section{PERCENTAGE OF FULLY IMMUNISED CHILDREN FOR FIVE SEPARATE COHORTS OF CHILDREN AGED 12 MONTHS TO LESS THAN 15 MONTHS BY AREA HEALTH SERVICE}

\begin{tabular}{|c|c|c|c|c|c|}
\hline Area health service & $\begin{array}{c}30 \text { June } 03 \\
\%\end{array}$ & $\begin{array}{c}30 \text { Sept } 03 \\
\%\end{array}$ & $\begin{array}{c}31 \mathrm{Dec} 03 \\
\%\end{array}$ & $\begin{array}{c}30 \text { March } 04 \\
\%\end{array}$ & $\begin{array}{c}30 \text { June } \\
\%\end{array}$ \\
\hline Central Coast & 92 & 93 & 95 & 92 & 91 \\
\hline Central Sydney & 90 & 90 & 89 & 89 & 90 \\
\hline Hunter & 95 & 93 & 94 & 95 & 93 \\
\hline Illawarra & 93 & 92 & 93 & 93 & 90 \\
\hline Northern Sydney & 91 & 91 & 90 & 91 & 89 \\
\hline South Eastern Sydney & 91 & 92 & 90 & 91 & 90 \\
\hline South Western Sydney & 90 & 91 & 90 & 91 & 91 \\
\hline Wentworth & 91 & 92 & 91 & 91 & 92 \\
\hline Western Sydney & 90 & 91 & 91 & 90 & 90 \\
\hline Far West & 88 & 91 & 93 & 88 & 89 \\
\hline Greater Murray & 94 & 93 & 93 & 93 & 94 \\
\hline Macquarie & 94 & 93 & 93 & 93 & 92 \\
\hline Mid North Coast & 89 & 90 & 91 & 89 & 90 \\
\hline Mid Western & 93 & 94 & 91 & 94 & 93 \\
\hline New England & 92 & 95 & 95 & 93 & 91 \\
\hline Northern Rivers & 84 & 85 & 84 & 85 & 85 \\
\hline Southern & 91 & 92 & 89 & 91 & 90 \\
\hline NSW & 91 & 91 & 91 & 91 & 91 \\
\hline Australia & 91 & 92 & 91 & 91 & 91 \\
\hline
\end{tabular}

\section{TABLE 2}

PERCENTAGE OF FULLY IMMUNISED CHILDREN IDENTIFIED AS ABORIGINAL OR TORRES STRAIT ISLANDER, FOR FIVE SEPARATE COHORTS OF CHILDREN AGED 12 MONTHS TO LESS THAN 15 MONTHS

\begin{tabular}{|c|c|c|c|c|c|}
\hline & $\begin{array}{c}30 \text { June } 03 \\
\%\end{array}$ & $\begin{array}{c}30 \text { Sept } 03 \\
\%\end{array}$ & $\begin{array}{c}31 \mathrm{Dec} 03 \\
\%\end{array}$ & $\begin{array}{c}31 \text { March } 04 \\
\%\end{array}$ & $\begin{array}{c}30 \text { June } \\
\%\end{array}$ \\
\hline NSW & 84 & 88 & 85 & 83 & 85 \\
\hline Australia & 84 & 87 & 82 & 83 & 84 \\
\hline
\end{tabular}

Source: Australian Childhood Immunisation Register. 
vaccinated late or to service providers failing to forward information to the ACIR. ${ }^{1}$ Table 2 details the percentage of fully immunised children identified as Aboriginal or Torres Strait Islander in New South Wales for the same cohort, reported by all service providers.

\section{Reference}

1. Hull B, Lawrence G, MacIntyre C, McIntyre P. Immunisation coverage in Australia corrected for under-reporting to the Australian Childhood Immunisation Register. Aust NZJ Public Health 2003; 27(5): 533-38.

\section{INTRODUCTION OF SCHOOL-BASED VACCINATION PROGRAMS IN NSW}

\section{Melanie Boomer and Sue Campbell-Lloyd}

In August 2003, NSW Health implemented the National Meningococcal C Vaccination Program, to provide free meningococcal $\mathrm{C}$ vaccine to all 6-19 year olds through school-based clinics by December 2004.

In May 2004, school-based vaccinations services were expanded, with the introduction of the NSW Adolescent Vaccination Program. This program provides a course of hepatitis B vaccine to Year 7 students, and a new diphtheria-tetanus-pertussis (dTpa) vaccine for adolescents to all high school students.

\section{TABLE 3}

NATIONAL MENINGOCOCCAL C VACCINATION PROGRAM FOR ALL 6-19 YEAR OLDS, SCHOOLBASED VACCINATIONS, NSW, RESULTS FOR PERIOD 4 AUGUST 2003 TO 2 JULY 2004

\begin{tabular}{|lc|}
\hline Area health service & $\begin{array}{c}\text { Total number of students } \\
\text { aged 6-19 years vaccinated }\end{array}$ \\
\hline Central Coast & 29749 \\
Central Sydney & 31208 \\
Far West & 5658 \\
Greater Murray & 35616 \\
Hunter & 76455 \\
Illawarra & 33747 \\
Macquarie & 15865 \\
Mid North Coast & 38435 \\
Mid Western & 25684 \\
New England & 24487 \\
Northern Rivers & 34693 \\
Northern Sydney & 54510 \\
South Eastern Sydney & 47178 \\
South Western Sydney & 73266 \\
Southern & 22628 \\
Wentworth & 26715 \\
Western Sydney & 55855 \\
Total & 631749 \\
\hline This report reflects data processed by the NSW Immunisation \\
Unit up until 4.00 p.m. Friday 2 July 2004. Data are \\
provisional and subject to ongoing revision and review. \\
\end{tabular}

School-based vaccination services are being implemented by the NSW Health Immunisation Unit and the Immunisation Coordinators in each area health service. Information regarding the number of students vaccinated with each vaccine is provided to the Immunisation Unit daily and a cumulative summary is published weekly on the NSW Department of Health internet site.

Tables 3-5 provide a summary of the number of students vaccinated during the school clinics to date in each of these programs.

\section{MONITORING OF ADVERSE EVENTS FOLLOWING IMMUNISATION FORTHE SCHOOL-BASED NATIONAL MENINGOCOCCAL CVACCINATION PROGRAM IN NSW}

\section{Melanie Boomer and Sue Campbell-Lloyd}

An integral component of the National Meningococcal C Vaccination Program is the surveillance of Adverse Events Following Immunisation (AEFIs).

AEFIs relating to vaccinations that are undertaken in schools are monitored using two surveillance methods:

- AEFIs that occur after the Program nursing staff have left the school on the clinic day are reported by providers such as general practitioners to public health

\section{TABLE 4}

NSW ADOLESCENT VACCINATION PROGRAM FOR ALL HIGH SCHOOL STUDENTS, SCHOOL-BASED DIPHTHERIA-TETANUS-PERTUSSIS VACCINATIONS, NSW, RESULTS FOR THE PERIOD 3 MAY 2004 TO 2 JULY 2004

\begin{tabular}{|lc|}
\hline Area health service & $\begin{array}{c}\text { Total number of high } \\
\text { school students vaccinated }\end{array}$ \\
\hline Central Coast & 4512 \\
Central Sydney & 3190 \\
Far West & 539 \\
Greater Murray & 4158 \\
Hunter & 9152 \\
Illawarra & 4780 \\
Macquarie & 3041 \\
Mid North Coast & 11676 \\
Mid Western & 6524 \\
New England & 1305 \\
Northern Rivers & 6945 \\
Northern Sydney & 4692 \\
South Eastern Sydney & 4754 \\
South Western Sydney & 9517 \\
Southern & 3100 \\
Wentworth & 1213 \\
Western Sydney & 4597 \\
Total & 83695 \\
\hline This report reflects data processed by the NSW Immunisation \\
Unit up until 4.00 p.m. Friday July 2004. Data are \\
provisional and subject to ongoing revision and review. \\
\end{tabular}




\section{TABLE 5}

NSW ADOLESCENT VACCINATION PROGRAM FOR YEAR 7 STUDENTS, SCHOOL-BASED HEPATITIS B VACCINATIONS, RESULTS FOR THE PERIOD 3 MAY 2004 TO 2 JULY 2004

\begin{tabular}{|lc|}
\hline Area health service & $\begin{array}{c}\text { Total number of } \\
\text { Year 7 }\end{array}$ students vaccinated \\
\hline Central Coast & 1828 \\
Central Sydney & 2415 \\
Far West & 141 \\
Greater Murray & 1545 \\
Hunter & 3099 \\
Illawarra & 2082 \\
Macquarie & 662 \\
Mid North Coast & 2195 \\
Mid Western & 768 \\
New England & 917 \\
Northern Rivers & 1884 \\
Northern Sydney & 4664 \\
South Eastern Sydney & 3913 \\
South Western Sydney & 4189 \\
Southern & 1259 \\
Wentworth & 2135 \\
Western Sydney & 4919 \\
Total & 38615 \\
\hline This report reflects data processed by the NSW Immunisation \\
Unit up until 4.00 p.m. Friday 2 July 2004. Data are \\
provisional and subject to ongoing revision and review. \\
\end{tabular}

units, and are entered onto the Notifiable Diseases Database maintained by the Communicable Diseases Branch of the NSW Department of Health. These notifications are transferred to the Adverse Drug Reactions Advisory Committee-a subcommittee of independent medical experts that advises the Therapeutic Goods Administration on the safety of medicines - for review and assignment of a causality rating before being returned to the NSW Department of Health;

- AEFIs (classified as anaphylaxis, seizure, severe allergic reaction, severe headache, severe local reaction, or 'other') that occur during the school clinic are reported by the Program nursing staff directly to the NSW Department of Health each day. Severe AEFIs (that is, anaphylaxis) are notified by phone immediately to the Department. These notifications are reviewed by an expert panel and forwarded to Adverse Drug Reactions Advisory Committee for assignment of a causality rating. This notification system allows surveillance of any immediate reactions and also ensures that events that are specific to the environment of the school clinic are reported and investigated in a timely manner.

Figure 1 provides information regarding the AEFIs that occurred at the school-based vaccination clinics between August 2003 and June 2004 in NSW. During this period,

\section{FIGURE 1}

DISTRIBUTION OF ADVERSE EVENTS FOLLOWING IMMUNISATION, MOST SERIOUS REACTION REPORTED AT SCHOOL-BASED CLINICS, NATIONAL MENINGOCOCCAL C VACCINATION PROGRAM, NSW, AUGUST 2003 TO JUNE $2004(N=148)$

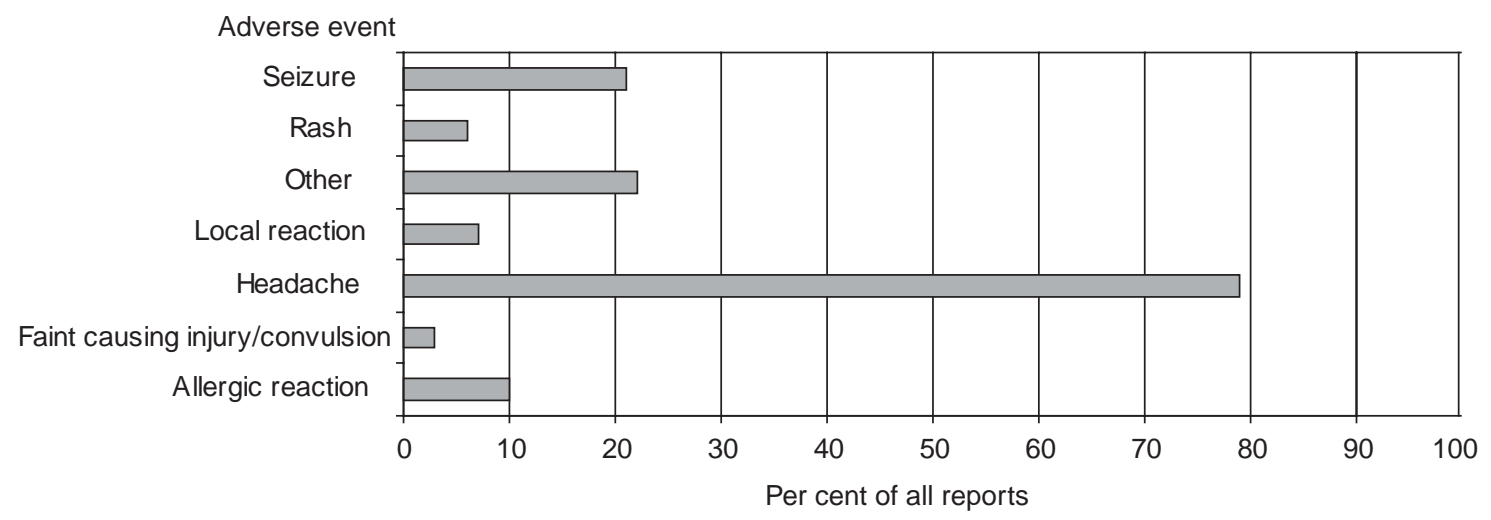

Source: Adverse Events Following Immunisation in School-based Vaccination Programs Database, NSW Department of Health 
631,749 children were vaccinated, with a total of 148 adverse events reported through the school-based surveillance system (a rate of 23 per 100,000 vaccinations). Headaches were reported most frequently, which is similar to the AEFI profile reported for the program in the United Kingdom. ${ }^{1}$ Also similar to the United Kingdom findings, the provision of meningococcal $\mathrm{C}$ conjugate vaccine to children and adolescents in a school setting is a safe and effective means to achieve high coverage in these age groups. ${ }^{1}$

\section{Reference}

1. Miller E, Salisbury D, Ramsay M. Planning, registration, and implementation of an immunisation campaign against meningococcal $\mathrm{C}$ disease in the UK: A success story. Vaccine 2002; 20: s8-s67.

\section{HIV INFECTIONS AND AIDS}

In the first three months of 2004, there were 112 people notified with newly-diagnosed HIV infection, 25 notified with AIDS, and four people who died following AIDS diagnosis in NSW (Table 6). Data on new HIV infections are being monitored closely to see whether the increases in notifications seen in NSW in 2002 and 2003 will be sustained in 2004. The proportions of the people notified with new HIV diagnoses in 2004 who were female (19 per cent) and who reported heterosexual sex as their most likely means of infection ( 22 per cent) are both slightly higher than in 2003. 


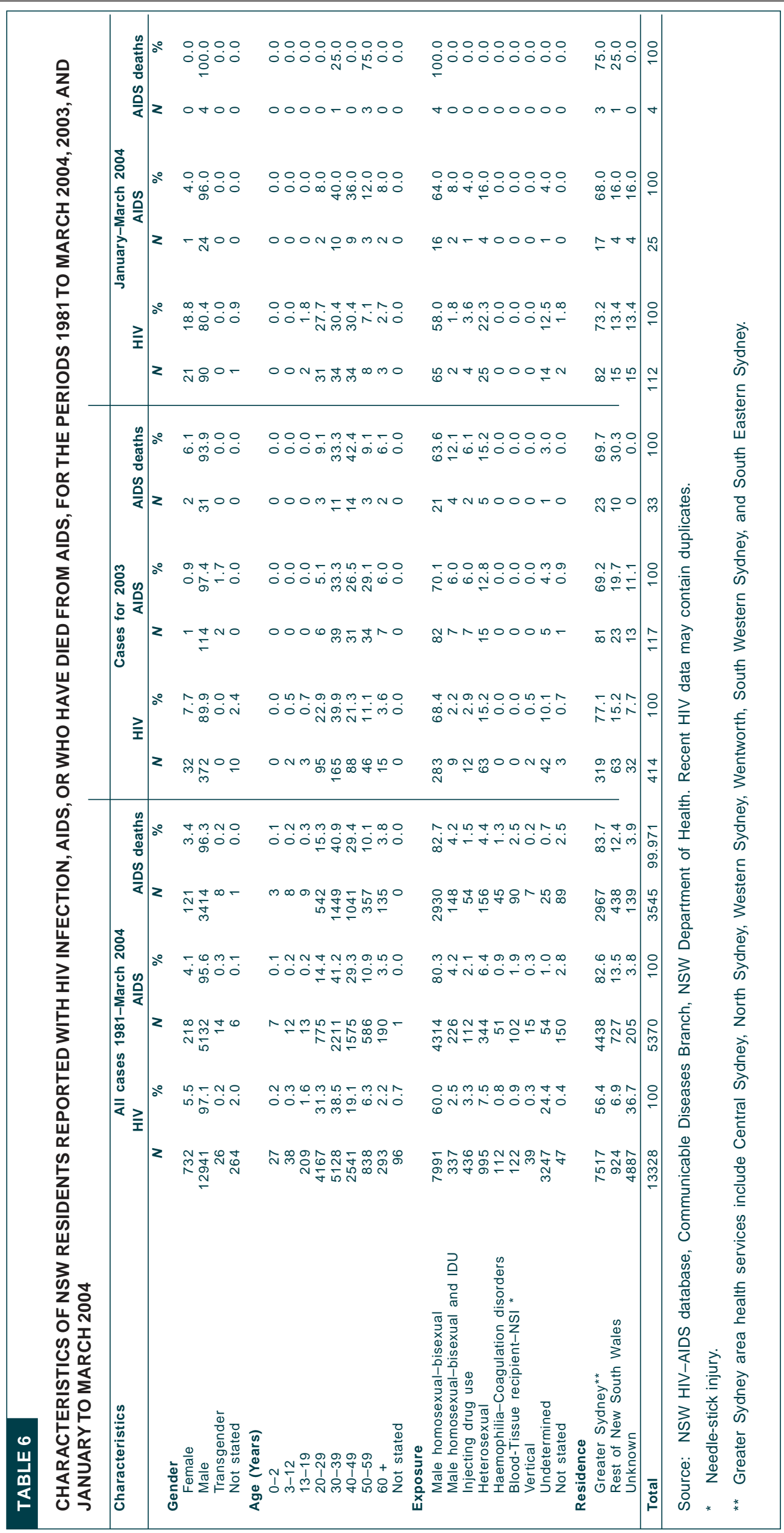




\section{FIGURE 1}

\section{REPORTS OF SELECTED COMMUNICABLE DISEASES, NSW, JAN 1999 TO JUNE 2004, BY MONTH OF ONSET}

Preliminary data: case counts in recent months may increase because of reporting delays.

Laboratory-confirmed cases only, except for measles, meningococcal disease and pertussis $\mathrm{BFV}=$ Barmah Forest virus infections, RRV = Ross River virus infections

lab+ = laboratory confirmed
Men Gp C and Gp B = meningococcal disease due to serogroup $C$ and serogroup $B$ infection, other/unk $=$ other or unknown serogroups. NB: multiple series in graphs are stacked, except gastroenteritis outbreaks.

NB. Outbreaks are more likely to be reported by nursing homes \& hospitals than from other institutions

\begin{tabular}{|rc|}
\hline \multicolumn{3}{|c|}{ NSW population } \\
Male & $50 \%$ \\
$<5$ & $7 \%$ \\
$5-24$ & $28 \%$ \\
$25-64$ & $52 \%$ \\
$65+$ & $13 \%$ \\
Rural $^{*}$ & $42 \%$ \\
\hline
\end{tabular}

cases

Apr 04-Jun 04

Male $52 \%$

$<5 \quad 1 \%$

$25-64 \quad 84 \%$

$\begin{array}{rr}5-64 & 84 \% \\ 65+ & 10 \%\end{array}$

Rural $95 \%$

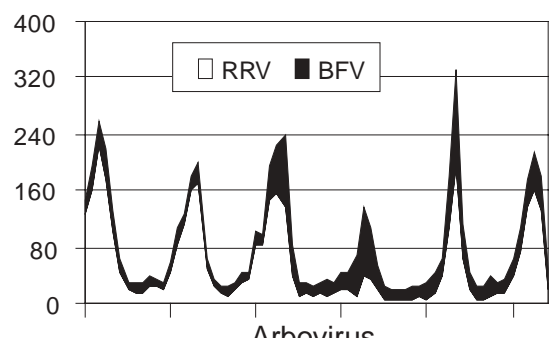

Arbovirus

\begin{tabular}{|rc|}
\hline \multicolumn{2}{|c|}{ Apr 04-Jun 04 } \\
Male & $52 \%$ \\
$<5$ & $45 \%$ \\
$5-24$ & $14 \%$ \\
$25-64$ & $36 \%$ \\
$65+$ & $5 \%$ \\
Rural & $55 \%$ \\
\hline
\end{tabular}

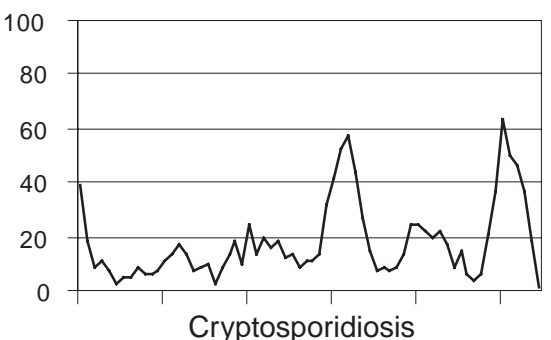

\begin{tabular}{|cc|}
\hline \multicolumn{2}{|c|}{ Apr 04-Jun 04 } \\
Male & $82 \%$ \\
$<5$ & $0 \%$ \\
$5-24$ & $27 \%$ \\
$25-64$ & $71 \%$ \\
$65+$ & $2 \%$ \\
Rural & $21 \%$ \\
\hline
\end{tabular}

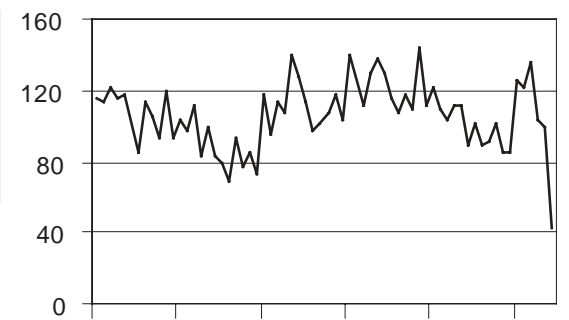

Gonorrhoea
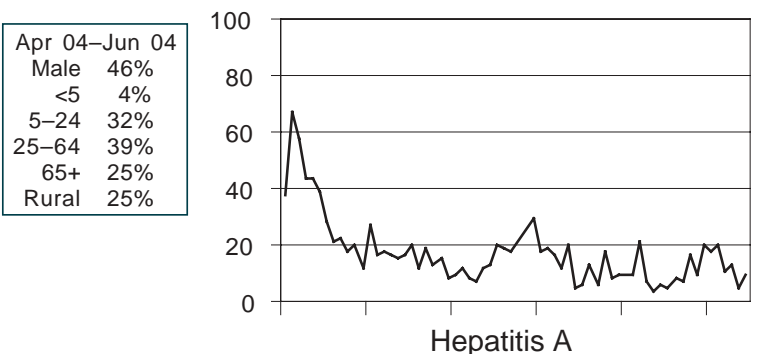

Hepatitis A

\begin{tabular}{|c|c|}
\hline Apr 04-Jun 0 & 04 \\
\hline All outbreaks & 180 \\
\hline Nursing homes 1 & 127 \\
\hline Hospitals & 36 \\
\hline Child care & 11 \\
\hline Schools & 2 \\
\hline Other & 4 \\
\hline
\end{tabular}

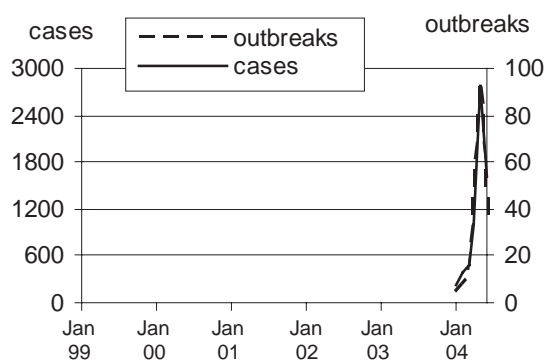

Gastroenteritis outbreaks in institutions
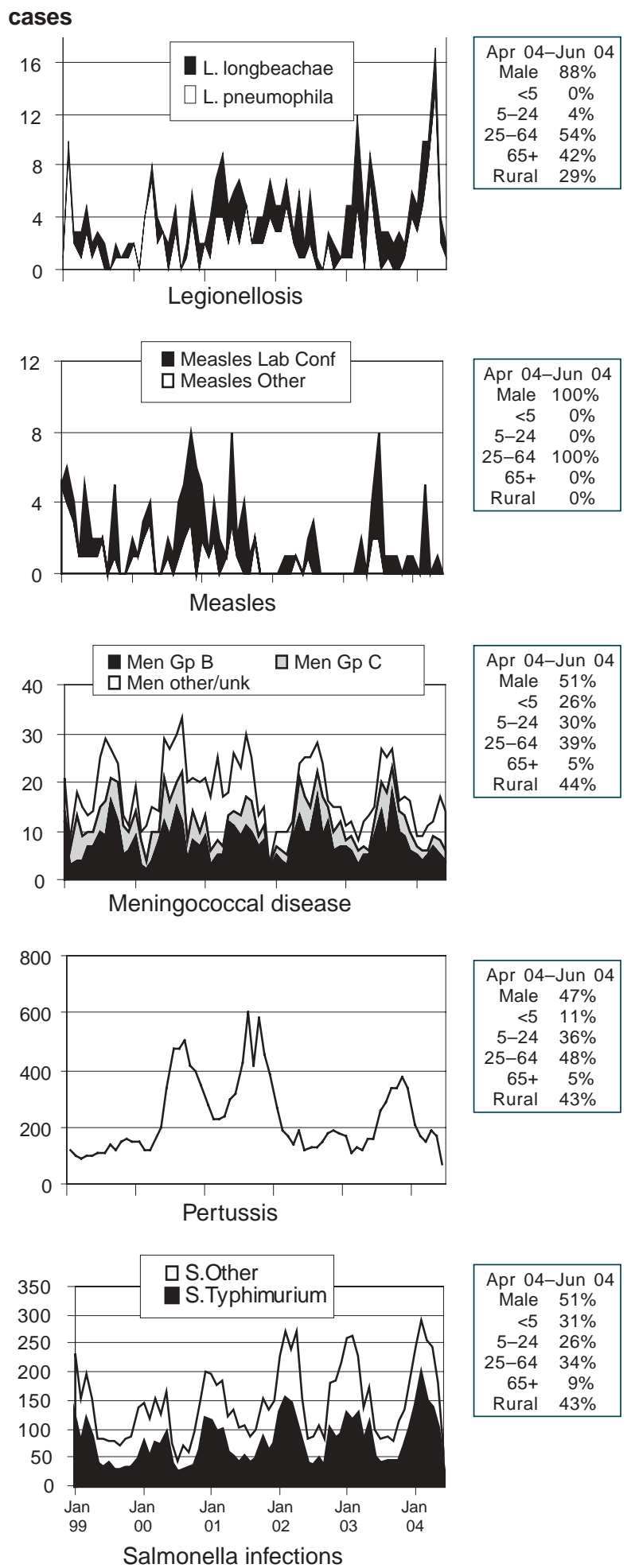


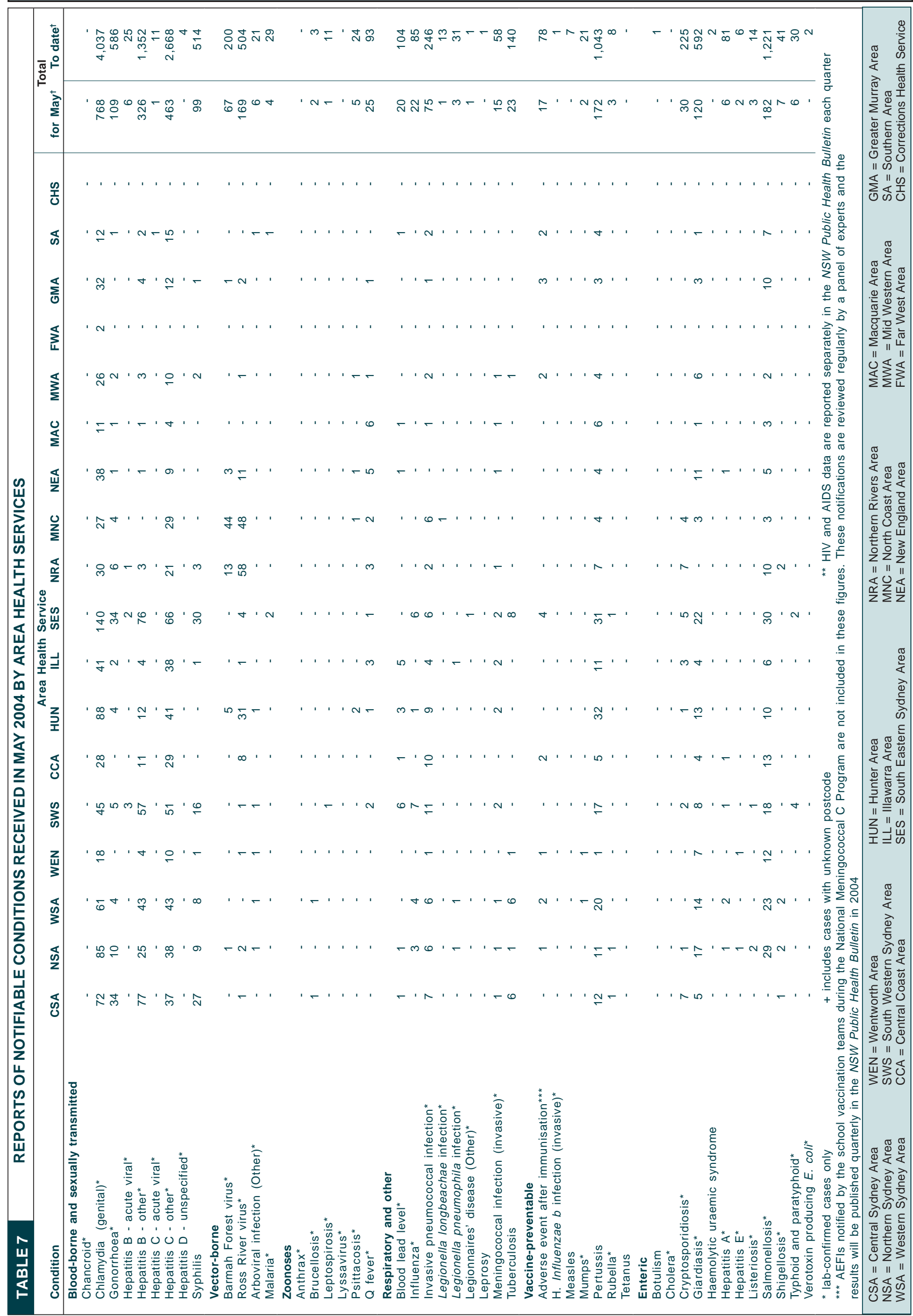




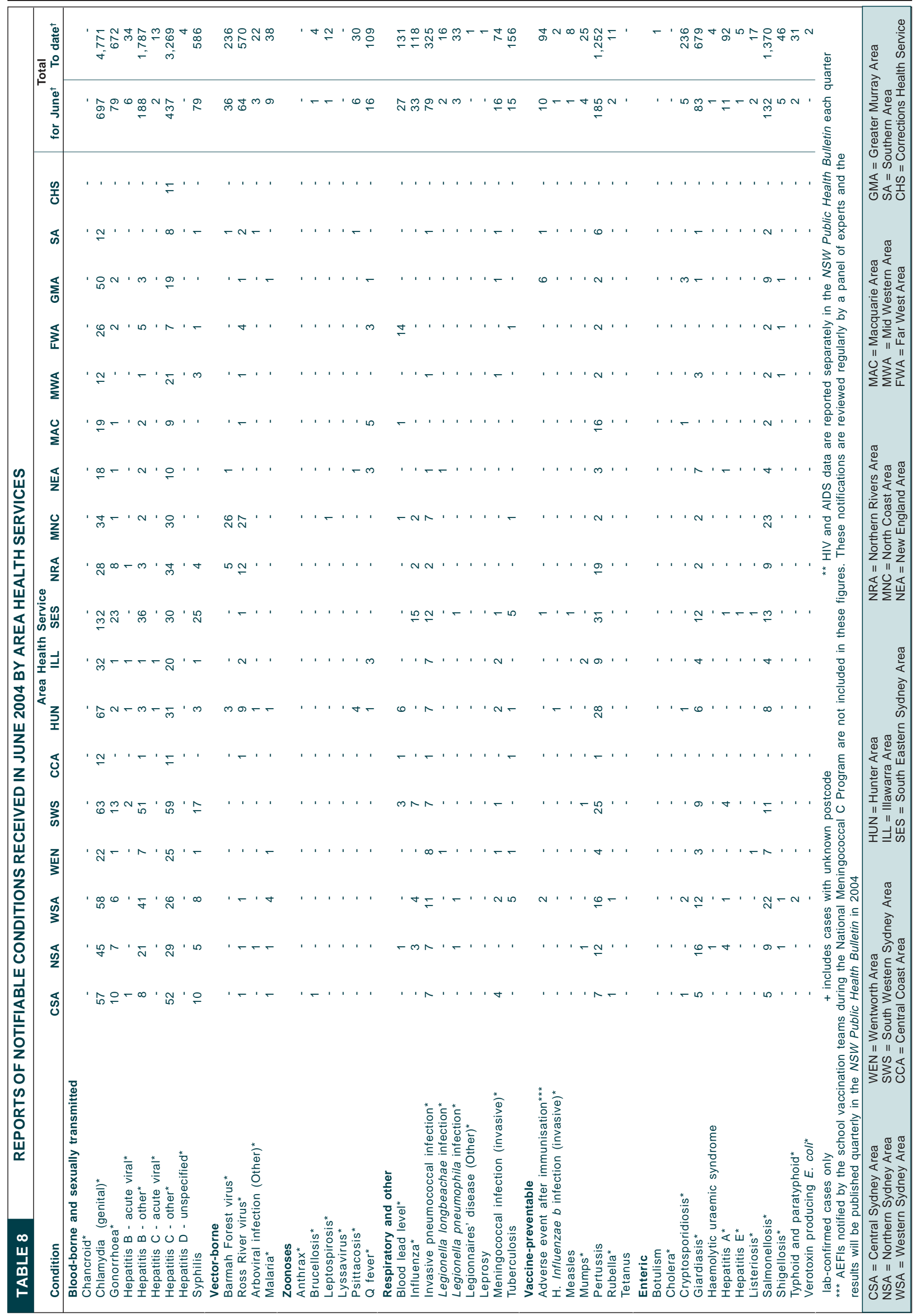

